\title{
Let there be LIGHT
}

\section{There are all sorts of sources of light in the practice. Stephen Hancocks flicks}

\section{a switch or two.}

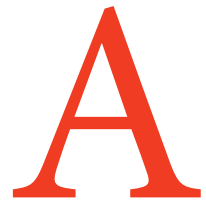

famous Hollywood actress was once asked what the secret of beauty was. 'That', she pouted, 'is easy. There are two essential ingredients, distance and lighting.' Now whether or not that same duo is present in your practice depends on how big design has dictated. Mind you, I use the word design with caution as many practices come as close to good taste as an iceberg does to the equator.

Before electricity, dental chairs had to be placed facing windows so that natural light could be used to help the dentist gaze into the pink and white (and dark) depths of the patient's mouth. Presumably the dental team, such as they would have been in those days, looked forward very much to winter when the short days would have put paid to anything approaching complicated treatment after about three-thirty in the afternoon. Perhaps dentures by the wavering murk of candle flame might just have been possible but otherwise it would have been home on the horse-drawn bus by teatime. What bliss. Summer of course would have been quite a different matter: 'stoppings for the teeth' and painless extractions being traded through until nearly $10 \mathrm{pm}$ when the twilight flushed in through the net the space is and exactly what sort of lighting the

curtains and mellowed in ruby rays off the shiny white bracket table.

I suppose too, that properties with bay windows would have been much in demand as dental premises as the chair could be turned to face the ambient light as the day progressed, perhaps even with a patient in the chair as a longer course of treatment plodded on and on with the incumbent being swivelled round, mouth ajar rather like a clown in one of those end of pier amusement arcades at which pingpong balls are aimed.

No longer. With the discovery of electricity and the invention of the light bulb everything changed with a flick of the switch. The operating light now meant that the surgery could be redesigned completely, not even needing a window at all - sound familiar? - treatment to take place at any point in the day, or night.

But who decides on the general lighting? The practice boss probably ... but what does it say about him or her? Rather like the game where you speculate on if someone was a colour what would they be (very brown? gorgeously yellow?) or a car (Saab or Skoda?) then what does a single dangling Pearl 60 watt say personality-wise? Especially with a dusty lampshade on top. What message does a standard lamp in the waiting room convey, a table lamp in the shape of a German shepherdess (with or without attendant flock) or an angle-poise clamped to the side of the reception desk with the bulb directly shining in the patient's face?

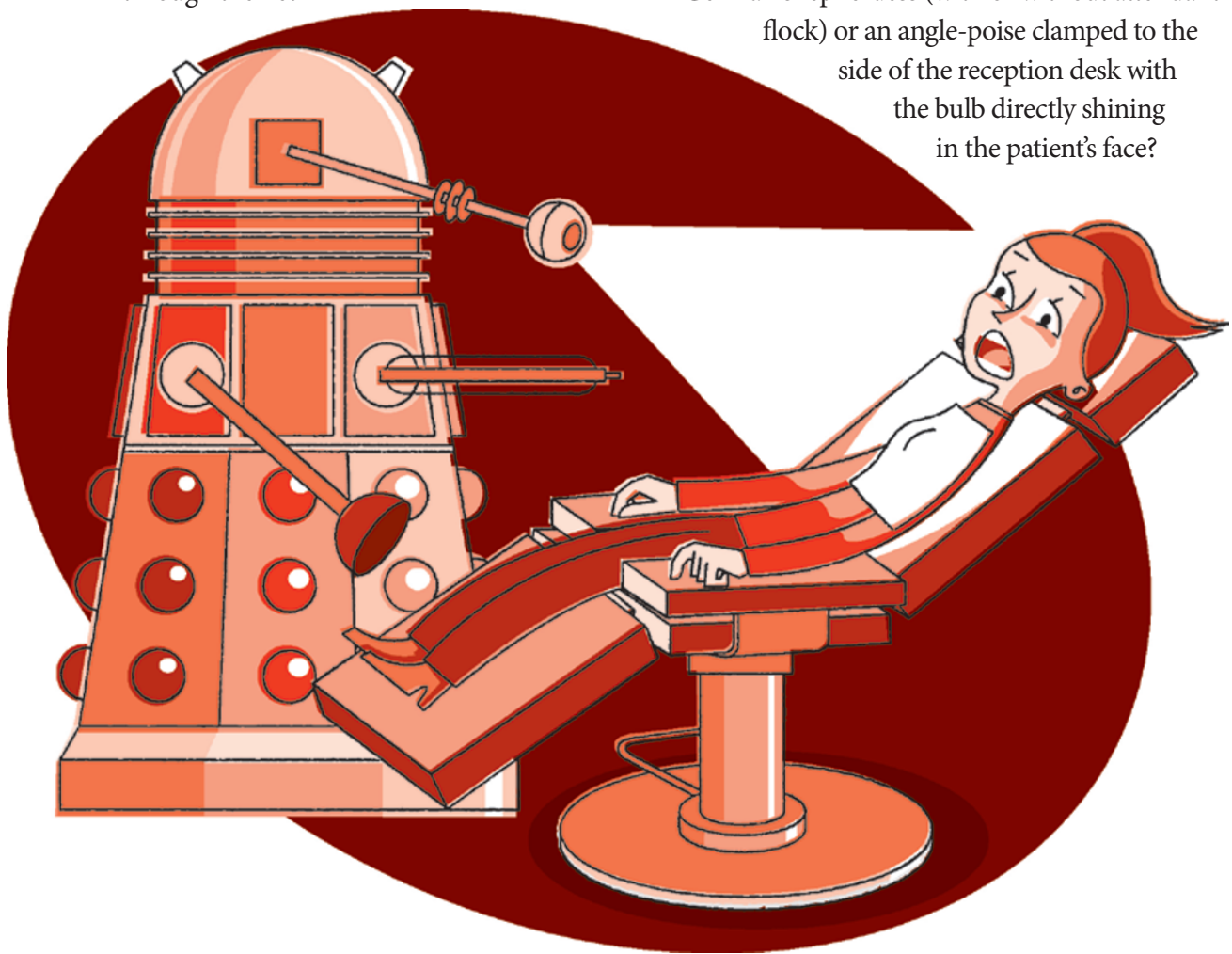

'What does a single dangling Pearl 60 watt with a dusty lampshade on top say personality wise?"

Conversely do you trust a principal whose idea of ideal environmental ambience is cool orange up-lighting met at halfway stage on the wall by screaming purple down-washers?

Not that sources of illumination are limited to the fixed variety. Headlamps made a bit of a minor comeback a few years ago and quite fetching they could look too. Combined with a spooky set of loupes, protective glasses and facemask it was a wonder that dentists weren't transformed into a new race of Dr Who monsters.

But light has been no slouch. It has muscled its way to the front of the queue and shone its way through several career changes, transforming itself from use merely as an aid to diagnosis to the heart of treatment itself: curing lights, lasers and bleaching beams to name but a few. Attendant with these are the health and safety precautions: funny-looking hand-held shields which resemble some Victorian lady's bridge party fan and the wonderful range of ghastly tinted specs.

But most importantly, light at work should serve every one of us and show us at our best to patients and team members alike. Feeling slightly the worse for wear after a hard night dancing, drinking or up with the children? You need a discreet, softer-focus light gently playing on your good side (okay, this morning on your least bad side) as you smile politely down at the patient while trying not to move your head too much. Dressed up at close of play for an evening out: now you want spotlights, lime light, disco lights (okay, not disco lights) to play off those sequins and catch the glitter on the handbag. Oh, but do remember that other alleged element of beauty - distance. Maybe you'd better keep a goodly stand off from your team mates after all; well, at least until you can reach for the dimmer switch. 